Received: August 29, 2017

Revision received: May 2, 2018

\title{
Selection of Cooperative Enterprises in Vocational Education Based on ANP*
}

\author{
Xueshi $\mathrm{Wu}^{1}$ \\ Jiangxi Science \& Technology \\ Normal University
}

\author{
Mengmeng Wang ${ }^{2}$ \\ Jiangxi Science \& Technology \\ Normal University
}

\begin{abstract}
Judging from the international successful experience and domestic policy orientation, school-enterprise cooperation has gradually become the key to improving the quality of vocational education. Accordingly, how to select the enterprise to participate in the vocational education has become a top challenge for schools. This paper uses the analytical network process (ANP) method to address this problem. As a practical decisionmaking method for complex problems, the ANP method determines the research objectives, selects the preferred evaluation indices, constructs the network structure, determines the relation matrix, builds the super matrix, and calculates the normalized feature vector of each index, i.e., the relative weight of each Level 3 indicator. According to the calculation results, suggestions are proposed: first, study and find out about the selection body of the enterprise involved in the vocational education, and then establish intermediary service agencies for school-enterprise cooperation in vocational education.
\end{abstract}

\section{Keywords}

ANP • Vocational Education • Selection of Enterprises

\footnotetext{
* The work was supported by the project of young top-notch in Jiangxi Science and Technology Normal University 2017, "The Research on the School-Enterprise Cooperation System of Vocational Education Based on Dual-Subject" (2017QNBJRC002).

${ }^{1}$ Correspondence to: Department of Faculty of Education, Tianjin University, Tianjin, 300350, China. Email: 18070033015@163.com

${ }^{2}$ Department of Faculty of Education, Jiangxi Science \& Technology Normal University, Nanchang 330038, China. Email: 18070033015@163.com
}

Citation: Wu, X. S. \& Wang, M. M, Mother-Child and Teacher-Child Relationships and Their Associations with School
Adjustment in Pre-school. Educational Sciences: Theory \& Practice, 18(5), $1507-1515$.
http://dx.doi.org/10.12738/estp.2018.5.047


Wu, Wang / Mother-Child and Teacher-Child Relationships and Their Associations with School Adjustment in Pre-school

It was pointed out in Guo-Fa (2014) No.19 Decision of the State Council on Accelerating the Development of Modern Vocational Education that: "it is necessary to study and formulate relevant regulations and incentive policies to promote school-enterprise cooperation, deepen integration of production and education, encourage the industries or enterprises to organize or participate in vocational education and give play to the important role of enterprises in education (The State Council of the People's Republic of China, 2014), which fully reflects the important position of enterprises in vocational education. However, this has raised an important question which companies can participate in vocational education, or can all companies, whether large or small, technologically advanced or not, participate in the vocational education as a major role? In other words, it is a matter of selecting the appropriate enterprise in vocational education.

At present, judging from the international successful experience and domestic policy orientation, it is imperative to study how to select the enterprises involved in vocational education. Firstly, according to the German regulations Federal Vocational Education Act, it is a right of an enterprise to participate in vocational education, but such enterprise must be investigated, evaluated and certified by the corporate training and consulting department of the industry association before it implements vocational training. The criteria used by the industry associations to select an enterprise include: (1) the enterprise has the training regulations and framework plan in place for the training-targeted occupation; (2) the enterprise has an overall training plan; (3) the enterprise's production type, products or services and production methods must meet the requirements for teaching of the required knowledge and skills specified in the training regulations; (4) the enterprise has sufficient equipment and devices for training, including machines, tools, instruments, and training materials; (5) the enterprise has an appropriate training venue; (6) the ratio of the number of trainees to the number of professionals in the enterprises should meet relevant regulations (Liu, 2011). Secondly, it was pointed out in Jiao-Zhi-Cheng (2015) No.7 Action Plan for Enhancing the Management Level of Vocational Schools (20152018)" that "efforts should be made to introduce excellent cultures into campus, promote the excellent traditional Chinese culture and modern industrial civilization, enhance the accumulation of technical skills and cultures, invite model workers, skilled workers and outstanding graduates, etc. to schools, bring industrial culture and excellent corporate culture into campus and develop students' career goals and professionalism" (Ministry and Education, 2015). In 2006, it was pointed out in the Implementation Opinions on Promoting Work-integrated Learning and Part-work and Part-study Program in Secondary Vocational Schools in Guangdong Province: "it is necessary to arrange students to take internships in large and medium-sized enterprises and institutions with advanced production technologies, strict management and standardized business practices, legal compliance and good reputations (Department of Education of Guangdong Province, 2006)".

\section{Research Tool}

Analytic Network Process (ANP) is a new decision analysis method proposed by Professor T.L. Saaty at the University of Pittsburgh in 1996. The ANP method uses a network-like structure rather than a simple hierarchical structure to represent the relationships among the elements in the system. This structure consists of a control layer and a network layer, among which, the control layer includes the problem objectives and decision criteria, while the network layer consists of all elements controlled by the control layer but interacting with and 
dominating each other. ANP can more accurately describe the relationship between the objective things, and thus it is a more effective decision-making method.

\section{Research Process}

(1) Determine the research objective. As the starting point and destination of the research, the research objective includes defining the research object, analyzing the research hypothesis, prescribing the research conditions, and determining the research indices. Regarding the selection of cooperative enterprises in vocational education, the research objective is to set up a preliminary index system for selection of cooperative enterprises in vocational education under certain evaluation hypotheses with the candidate cooperative enterprises as the research object.

Table 1

Criteria for selection and evaluation of cooperative enterprises in vocational education

\begin{tabular}{|c|c|}
\hline Level 1 indices & Level 2 indices \\
\hline \multirow{4}{*}{ 1. Future prospect (B1) } & 1. Overall prospect of the industry $(\mathrm{C} 11)$ \\
\hline & $\begin{array}{l}\text { 2. Percentage of re-investment from prior- } \\
\text { year corporate profit }(\mathrm{C} 12)\end{array}$ \\
\hline & 3. Capacity utilization level (C13) \\
\hline & 1. Technological innovation speed (C21) \\
\hline \multirow[t]{3}{*}{ 2. Core technology (B2) } & 2. $R \& D$ investment $(\mathrm{C} 22)$ \\
\hline & 3. Current technological level (C23) \\
\hline & 1. Annual average income $(\mathrm{C} 31)$ \\
\hline \multirow[t]{3}{*}{ 3. Business scale (B3) } & 2. Annual income ranking (C32) \\
\hline & 3. Number of employees(C33) \\
\hline & 1. Brand reputation $(\mathrm{C} 41)$ \\
\hline \multirow[t]{3}{*}{ 4. Corporate reputation (B4) } & 2. Product quality $(\mathrm{C} 42)$ \\
\hline & 3. Corporate customer service (C43) \\
\hline & 1.HR development policy (C51) \\
\hline \multirow[t]{3}{*}{ 5. Leadership's attitude (B5) } & 2.Workforce education level (C52) \\
\hline & 3. Senior management's support (C53) \\
\hline & 1. Corporate system (C61) \\
\hline \multirow{3}{*}{ 6. Corporate culture (B6) } & 2. Corporate value (C62) \\
\hline & 3. Corporate spirit (C63) \\
\hline & $\begin{array}{l}\text { 1. Participation in the school-enterprise } \\
\text { cooperation in the recent } 3 \text { years (C71) }\end{array}$ \\
\hline
\end{tabular}

Selection of cooperative enterprises in vocational education

(A)

7. Participation in the school- 2. Effect of school-enterprise cooperation in enterprise cooperation (B7) the recent 3 years(C72)

3. Intention to participate in the schoolenterprise cooperation in the future (C73)

Based on the target layer - selection of cooperative enterprises in vocational education (A), this study finally selects 7 Level 1 indices, i.e. B1-B7 and 21 Level 2 indices, i.e. C11-C13, C21-C23, C31-C33, C41- C43, C51C53, C61-C63 and C71-C73.

(2) Optimize the evaluation indices. The purpose of this step is to highlight the focus of evaluation, further optimize and improve evaluation indices, prevent the evaluation index system from being too complex and ensure the relevance of the evaluation indices. The author first used the indices for enterprise selection developed by three Taiwanese scholars - Sheu Hua Chen, Hung Tso Lin, and Hong Tau Lee - to form the preliminary evaluation index system (Sheu, Hung and Hong, 2004), and then submitted this index system to the 
domestic vocational education experts and heads of the school-enterprise cooperation office in occupational schools, who gave feedbacks anonymously on this system. After repeated consultation, summary and modification, the final evaluation indices were determined (as shown in Table 1).

(3) Construct the network structure. The selection of cooperative enterprises in vocational education is a complex decision-making process influenced by expert opinions, evaluation indices and evaluation methods. To apply the ANP method to the selection of cooperative enterprises in vocational education, a control layer and a network layer need to be constructed. Among the evaluation indices constructed in this study, 7 Level 1 indices - future prospect, core technology, business scale, corporate reputation, leadership's attitude, corporate culture and history of school-enterprise cooperation - influence, depends on and give feedbacks to each other. Therefore, in the network structure constructed in this study, there is only one control layer, i.e. selection of cooperative enterprises in vocational education, and the network layer consists of 7 Level 1 indices. The network structure shown in Figure 1:

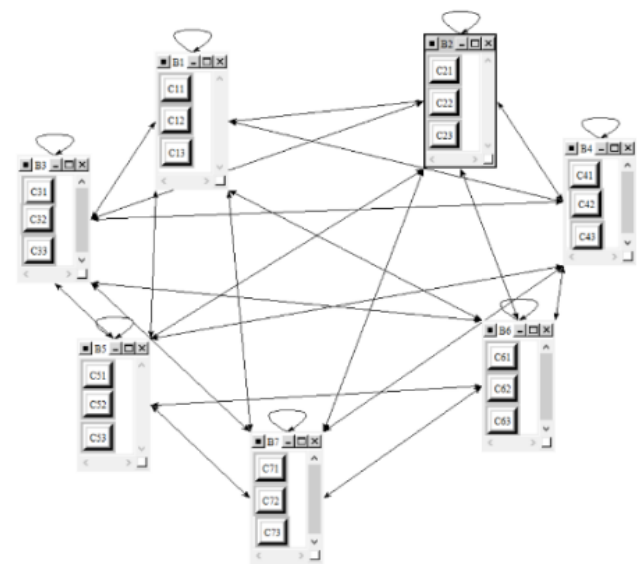

Figure 1. ANP model for selection of cooperative enterprises in vocational education

Table 2

Scale definition of the judgment matrix

\begin{tabular}{cl}
\hline Scale & \multicolumn{1}{c}{ Meaning } \\
\hline 1 & Equally important \\
2 & Between equally important and slightly important \\
3 & Slightly important \\
4 & Between slightly important and obviously important \\
5 & Obviously important \\
6 & Between obviously important and very important \\
7 & Very important \\
8 & Between very important and extremely important \\
9 & Extremely important \\
\hline
\end{tabular}

(4) Determine the relation matrix. In the ANP structure, the elements are interdependent on and interact with each other. Therefore, under each evaluation index criterion, the dominated index elements are compared in pairs. In this study, the expert scoring method is used to score the relationship between the index elements pairwise, and the relative importance of each pair of index elements is obtained. Then, a 9-point system (as shown in Table 2) is used to assign values to the selection indices of each enterprise and the matrix is established. Finally, the SD (Super Decision) software is used to calculate the weight of each selection index. 
(5) Construct the super matrix. The judgment matrix is constructed using a 9-point system, and the super matrix is constructed based on the judgment matrix. The principle is as follows:

In the element B1, with the element $\mathrm{C} 11$ as the criterion, the elements $\mathrm{C} 11, \mathrm{C} 12$, and $\mathrm{C} 13$ are compared with $\mathrm{C} 11$ in terms of indirect dominance according to the magnitude of its influence on $\mathrm{C} 11$, and the following judgment matrix is obtained:

Table 3

Judgment matrix

\begin{tabular}{lllll}
\hline C11 & C11 & C12 & C13 & Weight vector \\
\hline C11 & & & & \\
C12 & & & & \\
C13 & & & & \\
\hline
\end{tabular}

According to the above judgment matrix, an ordering vector $\left(\mathrm{w}_{11}^{(11)} \mathrm{w}_{12}^{(11)} \mathrm{w}_{13}^{(11)}\right) \mathrm{T}$ of the degrees of influence of the elements C11, C12 and C13 in the element set B1 on the element can be obtained. Similarly, with C12 or $\mathrm{C} 13$ as the criterion, the elements $\mathrm{C} 11, \mathrm{C} 12$, and $\mathrm{C} 13$ in the element set B1 are compared in terms of indirect dominance according to their influences on $\mathrm{C} 11$, and the corresponding judgment matrix can be constructed and the corresponding ordering vector can be obtained, i.e. the ordering vectors of the degrees of influence of $\mathrm{C} 11, \mathrm{C} 12$, and $\mathrm{C} 13$ on $\mathrm{C} 12$ and $\mathrm{C} 13$ in the element set B1 are: $\left(\mathrm{w}_{11}^{(12)} \mathrm{w}_{12}^{(12)} \mathrm{w}_{13}^{(12)}\right) \mathrm{T}$ and $\left(\mathrm{w}_{11}^{(13)} \mathrm{w}_{12}^{(13)} \mathrm{w}_{13}^{(13)}\right) \mathrm{T}$. According to the above three eigenvectors, the judgment matrix W11 is obtained:

$$
\mathrm{W} 11=\begin{array}{ccc}
\mathrm{w}_{11}^{(11)} & \mathrm{w}_{11}^{(12)} & \mathrm{w}_{11}^{(13)} \\
\mathrm{w}_{12}^{(11)} & \mathrm{w}_{12}^{(12)} & \mathrm{w}_{12}^{(13)} \\
\mathrm{w}_{13}^{(11)} & \mathrm{w}_{13}^{(12)} & \mathrm{w}_{13}^{(13)}
\end{array}
$$

Similarly, the judgment matrix Wij of the element sets B2, B3, B4, B5, B6, and B7 can be obtained (where $\mathrm{i}$ is $1,2,3,4,5$ or 6 ; and $\mathrm{j}$ is $1,2,3,4,5$ or 6 ). At the same time, a supermatrix $\mathrm{W}$ is constructed based on the above calculation results.

The constructed matrix $\mathrm{W}$ is not column normalized. Therefore, the relative weight of each column block in the supermatrix W needs to be determined. Each element group is seen as a whole, that is, an element, and then these element groups are compared pairwise to obtain the ordering vector of each element group with respect to other element groups, which is normalized. In this study, aij represents the degree of influence of the $\mathrm{i}$-th element group on the $\mathrm{j}$-th element group, and a weight matrix is obtained. A weighted supermatrix is constructed from the supermatrix $\mathrm{W}$ and the weight matrix $\mathrm{A}$, i.e., $\mathrm{W}^{\prime}=\mathrm{W} \cdot \mathrm{A}$.

The normalized eigenvector of $\mathrm{W}^{\prime}$ is calculated as $\mathrm{W}_{\infty}=(0.023772,0.022998,0.022998,0.080038$, $0.088314,0.099065,0.008438,0.008654,0.008547,0.015573,0.015692,0.015810,0.140246,0.102480$, $0.138198,0.045182,0.041757,0.038937,0.026182,0.029105,0.028015)$, which is the final weight of each Level 2 index in this model. 


\section{Results and Suggestions}

\section{(1) Research results}

Based on the processed data, all Level 2 indices are sorted in the descending order according to importance: HR development policy, senior management's support, workforce education level, current technological level, R\&D investment, technological innovation speed, corporate system, corporate value, corporate spirit, effect of school-enterprise cooperation in the recent 3 years, intention to participate in the school-enterprise cooperation in the future, participation in the school-enterprise cooperation in the recent 3 years, overall prospect of the industry, percentage of re-investment from prior-year corporate profit, capacity utilization level, corporate customer service, product quality, brand reputation, annual income ranking, number of employees and annual average income; and the Level 1 indices are sorted in the descending order: leadership's attitude, core technology, corporate culture, participation in school-enterprise cooperation, future prospect, corporate reputation and business scale.

\section{(2) Suggestions}

Based on the ANP method, this study solves the problem of relative weights of indices in the selection of enterprises to some extent. However, two important issues closely related to the selection of enterprises are not addressed - the selection body of the enterprise involved in the vocational education and the intermediary service agency. Through an in-depth analysis of the weight order of Level 2 indices, it can be found that the index ranking the first in the enterprise selection is the leadership's attitude; in other words, the success of schoolenterprise cooperation in vocational education depends on the leaders' personal subjective attitude, which is contrary to the "vocational" and "educational" nature of vocational education. The fundamental reason for this situation lies in the lack of intermediary service agencies for school-enterprise cooperation. Therefore, considering the above two problems, this paper proposes the following suggestions:

1. Study and clarify the selection bodies of the enterprises involved in vocational education. From the historical point of view, the selection bodies of enterprises did not emerge overnight, but through games between stakeholder organizations with the industrial transformation of the apprenticeship under different historical backgrounds of different countries. For example, the German apprenticeship stakeholder organizations mainly include traditional handicraft industry sector and modern industrial sector, guilds and trade unions as well as national intervention and trade autonomy (Wang, 2014). The British apprentice stakeholder organizations mainly include the emerging bourgeoisie and the ruling class, and the post-industrial-revolution artisan trade unions and capitalist associations (Wang, 2009). For the purpose of their interests, these stakeholder organizations would form their own action logics in the games (Zhang, 2014), thus shaping the trajectory of the apprenticeship industrialization. Here this paper briefly compares the important differences between the industrialization processes of apprenticeship in Germany and China, to see how the selection bodies of enterprises were formed.

1) Historical background. The development of guilds, especially craft guilds, has a profound historical background. In the 1860s, the tendency of liberalism in the German economy was mapped onto the apprenticeship field, resulting in the lifting of the strict restrictions on the establishment of hand workshops and the admission of apprentices in the apprenticeship legislation (Kathleen, 2010). As a result, workshop craftsmen 
Wu, Wang / Mother-Child and Teacher-Child Relationships and Their Associations with School Adjustment in Pre-school

could recruit large numbers of apprentices and even child labourers to reduce labour costs and obtain excess profits. In the 1970s, the social democratic labour movements broke out, prompting the conservative ruling party to actively support independent craftsmen to fight against the wave of labour movements (Volkov, 1978). On the other hand, the historical environment for the development of the traditional guilds in China was filled with challenges. In order to prevent the emergence of forces that can confront the state, the imperial dictators of the feudal dynasty strictly prohibited and controlled the behaviours of non-governmental organizations. The traditional guild organizations were not legalized and institutionalized until the late Qing Dynasty and early Republic of China. Despite being "politically weak", the guild organizations at that time were still economically strong.

2) Political background. German guilds have strong quasi-public power. In the 1880 s, the Reform Cycle Law was promulgated, giving the guild organizations more authority to control the apprenticeship and rule on the conflicts between employers, mechanics and trainees. The Handicraft Protection Act in 1897 stipulated that the guilds should be given greater control over the content and quality of apprenticeship training -apprenticeship contract control, skill certification system, and disqualification of apprentices failing the training (Schriewer, 1986). The quasi-public power laid the institutional foundation for the German guilds to control labour flow and obtain long-term cheap labour. At the same time, the authorities regarding skills certification and skills training also became the focus of competition in modern engineering industries, especially those skilldependent and traditional handicraft industries. In China, however, the political stance of the feudal dictatorship over civil organizations led to a high degree of autonomy within the guilds and their autonomy was only limited to the economic sphere but not to the political sphere. The conflicts between employees and employers in China were mainly about the wages and working conditions, and none of them involved the area of skill development.

Through the above comparison, it can be seen that the guilds in Germany being so strong has something to do with their profound historical and political backgrounds. This has laid an institutional foundation for the participation and certification of enterprises in vocational education. In contrast, the guilds in China have been weak since the beginning of their birth, and their strong autonomy has only existed within the industry. Therefore, it has been a huge challenge for them to enter the education field. Therefore, in the new context of the double-subject vocational education, enterprises that have undergone industry certification and chosen to participate in vocational education have lost their inherent advantages.

2. Establish intermediary service agencies for school-enterprise cooperation in vocational education. On May 2, 2014, Guofa [2014] No.19 Decision of the State Council on Accelerating the Development of Modern Vocational Education was issued, which pointed out that "efforts should be made to improve the enterprise participation system...encourage industries and enterprises to organize or participate in the organization of vocational education, and play the important role of enterprises in vocational education". This stipulation has pointed out the direction for the development of vocational education in the new era.

The reason for establishing intermediary service agencies for school-enterprise cooperation in vocational education is that the two subjects in the cooperation - vocational school and enterprise - are heterogeneous organizations. First, both the enterprises and the vocational schools are featured with "limited rationality," "opportunist behaviour tendency" and "asymmetric information" (which have been proposed by orthodox economics), leading to deviations from cooperative contracts (Hoffmann, 1963). An efficient intermediary 
service agency is the basic prerequisite for coordinating such deviation. Secondly, the resource-based theory believes that the competitive advantage of an organization comes from the organization's heterogeneous resources (Lu, 2003); in other words, the more heterogeneous resources a vocational school or enterprise has, the more competitive it will be. Compared with homogenous organizations, cooperating with heterogeneous ones requires higher transaction costs. So here the purpose of an intermediary service agency is to save the transaction costs, by substituting the low intra-organization transaction costs for the high external transaction costs (Jay, 1991). In summary, the organizations' deviations from contracts and the high transaction costs of cooperation with heterogeneous resources make it imperative to establish intermediary service agencies for school-enterprise cooperation.

The purpose of establishing an organization is to reduce transaction costs and improve the efficiency of resource allocation, and the selection of members of an intermediary service agency for school-enterprise cooperation must also follow this principle. Therefore, clarifying the sources of transaction costs has become the primary task in the establishment of an organization. The American economist Eifk G. Furubotn and the German economist Rudolf Richter proposed that: the transaction costs in the market can be mainly divided into three types: 1 . market transaction costs, that is, the trading party's costs of using the market, mainly including search and information costs, bargaining and decision-making costs and supervision and implementation costs; 2. management transaction costs, that is, the costs of implementing the labour contracts between the enterprise and its employees, including the costs of establishing, maintaining or changing an organizational design and the costs of running the organization; 3. political transaction costs, that is, the cost arrangements involved in the operation and adjustment of the institutional framework in the political system. Looking at the entire process of school-enterprise cooperation, vocational colleges and enterprises have something to do with market and management transaction costs, while the government agencies are related to political transaction costs. It can be seen that the intermediary service agency for school-enterprise cooperation in vocational education should include at least three organizations: vocational schools, enterprises, and government agencies.

Note: In this study, the selection of enterprises refers to the selection of enterprises for a specific major or major group, not involving the selection of majors.

\section{References}

Department of Education of Guangdong Province (2006). Implementation Opinions on Promoting Workintegrated Learning and Part-work and Part-study Program in Secondary Vocational Schools in Guangdong Province.

Hoffmann, E. (1963). Zur Geschichte der Berufsausbildung in Deutschland. Bielefeld: W. Bertelsmann.

Jay, B. B. (1991). Firm resources and sustained competitive advantage. Journal of Management, 17, 99-120.

Kathleen, T. (2010). How Institutions Evolve: The Political Economy of Skills in Germany, Britain, the United States, and Japan. Shanghai People's Publishing House: 201.

Liu, J. (2011). The Enterprise Training and Its Reference Significance under the Dual System of Germany. Contemporary Educational Science, (1), 55. 
Wu, Wang / Mother-Child and Teacher-Child Relationships and Their Associations with School Adjustment in Pre-school

Lu, X. X. (2003). The Western New Institutional Economics. China Development Press, 112, https://doi.org/10.1177/014920639101700108.

Ministry of Education (2015). Vocational School Management Level Improvement Action Plan (2015-2018).

Schriewer, J. (1986). Intermediare Instanzen, Selbstverwaltung und berufliche Ausbildungsstrukturen im historischen Vergleich. Zeitschrift fur Padagogie, 32(1), 69-90.

Sheu H. C., Hung T. L., Hong T. L. (2004). Enterprise partner selection for vocational education: analytical network process approach. International Journal of Manpower, (7), 645-646, https://doi.org/10.1108/01437720410563980.

The State Council of the People's Republic of China (2014). The Decision on Accelerating the Development of Modern Vocational Education.

Volkov, S. (1978). The Rise of Popular Antimodernism in Germany: The Urban Master Artisans,18731896.Princeton, NJ: Princeton University Press, 231.

Wang, X. (2009). Labour Security and Skill Formation. Jiangsu Social Sciences, (5), 107-113, https://doi.org/10.13858/j.cnki.cn32-1312/c.2009.05.038.

Wang, X. (2014). The Social Construction of Skill Formation: A Sociology Approach to the Evolving Trajectory of the Apprenticeship in China Factories. Social Sciences Academic Press, 109.

Zhang, B. (2014). Research on School-Enterprise Cooperation Governance under Multiple System Logic. Research in Education Development, (10), 44-50, https://doi.org/10.14121/j.cnki.1008-3855.2014.19.008. 